\title{
Sinopse das Orchidaceae do Parque Nacional de Boa Nova, BA, Brasil
}

\author{
Heloysa Tamillis do Rêgo ${ }^{1}$ e Cecília Oliveira de Azevedo ${ }^{1,2}$
}

Recebido: 7.6.2016; aceito: 9.12.2016

\begin{abstract}
Synopsis of the Orchidaceae of the Parque Nacional de Boa Nova, Bahia State, Brazil). The Parque Nacional de Boa Nova protects an important transition area between Caatinga and Atlantic Rainforest, and little is known about its flora. Thus, the present study aimed to survey the Orchidaceae in the Parque Nacional de Boa Nova. The survey was performed through monthly field trips. 42 species were found, distributed in 31 genera, including two new records the northeastern Brazil: Prosthechea allemanoides and Sarcoglottis ventricosa, and two new records to the State of Bahia: Malaxis parthonii and Trichosalpinx montana. Identification keys to genera and species, morphological and ecological observations are presented, along with data about geographical distribution of the species, contributing, with new information on the floristic composition of the Park.
\end{abstract}

Keywords: Atlantic Rainforest, Caatinga, Floristics, Mata de Cipó, Orchids

RESUMO - (Sinopse das Orchidaceae do Parque Nacional de Boa Nova, BA, Brasil) O Parque Nacional de Boa Nova protege uma importante área de transição entre a Caatinga e a Mata Atlântica e sua flora ainda é pouco conhecida. Desta forma, o presente estudo teve como objetivo realizar um levantamento florístico da família Orchidaceae no Parque Nacional de Boa Nova. O levantamento foi realizado através de excursões mensais a campo. Foram encontradas 42 espécies distribuídas em 31 gêneros, incluindo duas novas ocorrências para o Nordeste do Brasil: Prosthechea allemanoides e Sarcoglottis ventricosa, e dois novos registros para o estado da Bahia: Malaxis parthonii e Trichosalpinx montana. São apresentadas chaves de identificação para gêneros e espécies, observações morfológicas e ecológicas, além de dados sobre a distribuição geográfica das espécies, contribuindo, desta forma, com novas informações sobre a composição florística do Parque.

Palavras-chave: Caatinga, Florística, Mata Atlântica, Mata de Cipó, Orquídeas

\section{Introdução}

Orchidaceae Juss. abrange cerca de $7 \%$ das angiospermas, sendo considerada uma das maiores famílias desse grupo (Dressler 1993), com cerca de 25.000 espécies (Chase et al. 2003) distribuídas em 736 gêneros (Chase et al. 2015). O território brasileiro é representado por 2.495 espécies e 221 gêneros, destas 536 espécies e 128 gêneros ocorrem no Estado da Bahia (Barros et al. 2016). Neste Estado, foram realizados vários inventários florísticos com a família Orchidaceae, entre eles Toscano de Brito $(1995,1998)$, Toscano de Brito \& Queiroz (2003), van den Berg \& Azevedo (2005) e Azevedo \& van den Berg (2007), sendo a grande parte destes na Chapada Diamantina. Poucos inventários com Orchidaceae foram realizados em áreas mais secas e no sudoeste da Bahia (e.g. Azevedo \& Marinho 2012 e Marinho \& Azevedo 2011, 2013).
A família Orchidaceae pode ser encontrada em todo o planeta, com exceção das regiões polares (Dressler 1993). É dividida em cinco subfamílias: Apostasioideae Garay, Vanilloideae Szlach., Cypripedioideae Garay, Orchidoideae Lindl. e Epidendroideae Lindl. (Chase et al. 2015). A família Orchidaceae, apesar de apresentar uma grande diversidade morfológica, é facilmente reconhecida por suas flores, que apresentam uma pétala modificada, chamada de labelo, a presença do ginostêmio e os grãos de pólen agrupados em políneas (Dressler 1993).

O Parque Nacional de Boa Nova (PNBN) está localizado na região nordeste do Planalto da Conquista, no Estado da Bahia, nos limites dos municípios de Boa Nova, Manoel Vitorino e Dario Meira. O Parque foi criado em junho de 2010, e possui cerca de 12.000 hectares, tendo como objetivo proteger uma importante área de transição entre a Caatinga e

1. Universidade Estadual do Sudoeste da Bahia, Departamento de Ciências Naturais, Estrada do Bem-Querer, Km 4, s/n, Bairro Universitário, 45.083-900 Vitória da Conquista, Bahia, Brasil

2. Autor para correspondência: cazevedo@uesb.edu.br 
a Mata Atlântica, formado por um tipo particular de Mata Semidecidual conhecida localmente como Mata de Cipó (Brasil 2010).

O PNBN apresenta altitude variando entre $440 \mathrm{e}$ $1.111 \mathrm{~m}$ acima do nível do mar e temperatura média anual de $23{ }^{\circ} \mathrm{C}$, sendo a máxima de $26^{\circ} \mathrm{C}$ e a mínima de $14{ }^{\circ} \mathrm{C}$. A precipitação média é de $1.300 \mathrm{~mm} / \mathrm{ano}$ e a vegetação é bastante heterogenia, apresentando Caatinga, Mata de Cipó (Floresta Semidecidual Submontana) e Mata Atlântica (Floresta Ombrófila Montana). Estas fitofisionomias se apresentam em faixas paralelas de oeste para leste respectivamente (Brasil 2016).

A Mata de Cipó, como o nome sugere, é caracterizada por possuir grande quantidade de lianas (Mariano-Neto 2005). Além disso, é caracterizada pelo porte baixo, dossel com cerca de 12 metros de altura e em sua composição florística, destacam-se os gêneros Aspidosperma, Piptadenia, Caesalpinia, Pisonia, Tabebuia e Astronium (Novaes et al. 2007).

Recentemente duas espécies novas de plantas foram descritas para o Parque, Myrcia alatiramea Sobral \& E. Lucas (Myrtaceae) (Sobral et al. 2015) e Physeterostemon gomesii Amorim \& R. Goldenb. (Melastomataceae) (Amorim et al. 2014) ambas endêmicas do PNBN, demonstrando a importância de se conhecer a área. Desta forma, este trabalho teve como objetivo inventariar as Orchidaceae do PNBN.

\section{Material e métodos}

As coletas foram realizadas mensalmente no período de janeiro de 2012 a maio de 2014, percorrendo áreas da Mata Atlântica, Mata de Cipó (figura $1 \mathrm{a}-\mathrm{b}$ ) e Caatinga do PNBN. Mapa com a delimitação do Parque pode ser encontrado no site do ICMBIO. O material coletado foi desidratado e herborizado (Morri et al. 1989) e algumas flores conservadas em solução alcoólica (70\% álcool: $30 \%$ água), além disso folhas ou flores foram armazenadas em sílica gel, para estudos posteriores. As exsicatas foram depositadas no Herbário da Universidade Federal da Bahia (HVC). Visando a identificação dos táxons, foram consultadas literatura especializada e o sistema de classificação adotado foi o de Chase et al. (2015). Chaves taxonômicas foram elaboradas para a identificação dos gêneros e das espécies existentes no local de estudo, utilizando apenas os caracteres morfológicos externos. Análises morfológicas foram feitas a partir do material coletado. Os dados de fenologia foram obtidos dos dados de coleta.
Para analisar o Status de conservação das plantas coletadas no Parque foi consultado o Centro Nacional de Conservação da Flora (CNCFlora 2016). Comentários foram feitos para as espécies avaliadas ou quando propicio.

\section{Resultados e Discussão}

Foram encontradas 42 espécies de orquídeas no PNBN, distribuídas em 31 gêneros. Destas, 28 espécies foram coletadas na área de Mata Atlântica, 20 na Mata de Cipó, e três na Caatinga. Cyrtopodium flavum Link \& Otto ex Rchb., Epidendrum secundum Jacq., Gomesa flexuosa (Lodd.) M.W. Chase \& N.H. Williams, Oceoclades maculata (Lindl.) Lindl. e Prescottia plantaginifolia Lindl. ex Hook. foram coletadas tanto na área de Mata de Cipó quanto na área de Mata Atlântica. Já Catasetum luridum Lindl. e Vanilla palmarum (Salzm. ex Lindl.) Lindl. foram encontradas tanto na área de Caatinga como na área de Mata de Cipó.

Gomesa R.Br. e Epidendrum L. foram os gêneros mais representativos, com cinco e quatro espécies respectivamente, seguidos por Prosthechea Knowles \& Westc. com três espécies e Campylocentrum Benth., Stelis Sw. e Trichocentrum Poepp. \& Endl. com duas espécies cada, todos os outros gêneros apresentaram apenas uma espécie na área de estudo.

Quanto ao hábito, a maioria das espécies encontradas no Parque são epífitas, seguidas de espécies que podem ser rupícola ou terrícola, encontradas nas áreas de afloramento rochoso, e das terrícolas, e.g. Malaxis parthonii C. Morren, Prescottia plantaginifolia, Sacoila lanceolata (Aubl.) Garay. e Sarcoglottis ventricosa (Vell.) Hoehne.

Das espécies encontradas no Parque, Prosthechea allemanoides (Hoehne) W.E. Higgins e Sarcoglottis ventricosa são novas ocorrências para o Nordeste. Além destas, Malaxis parthonii e Trichosalpinx montana (Barb.Rodr.) Luer são registradas pela primeira vez para o Estado da Bahia.

A maioria das espécies encontradas no PNBN não foi avaliada pelo CNCFlora quanto ao Status de conservação. Campylocentrum crassirhizum Hoehne, Cyrtopodium flavum, Epidendrum carpophorum Barb. Rodr., Epidendrum secundum, Gomesa gravesiana (Rolfe) M.W. Chase \& N.H. Williams, Heterotaxis sessilis (Sw.) F. Barros, Jacquiniella globosa (Jacq.) Schltr, e Malaxis parthonii foram classificadas como LC, ou seja, pouco preocupante. Além destas, Rauhiella silvana Toscano foi avaliada como em perigo (EN). Pabstiella brasilica Luer \& Toscano não foi avaliada pelo CNCFlora, contudo é uma espécie aparentemente rara. 

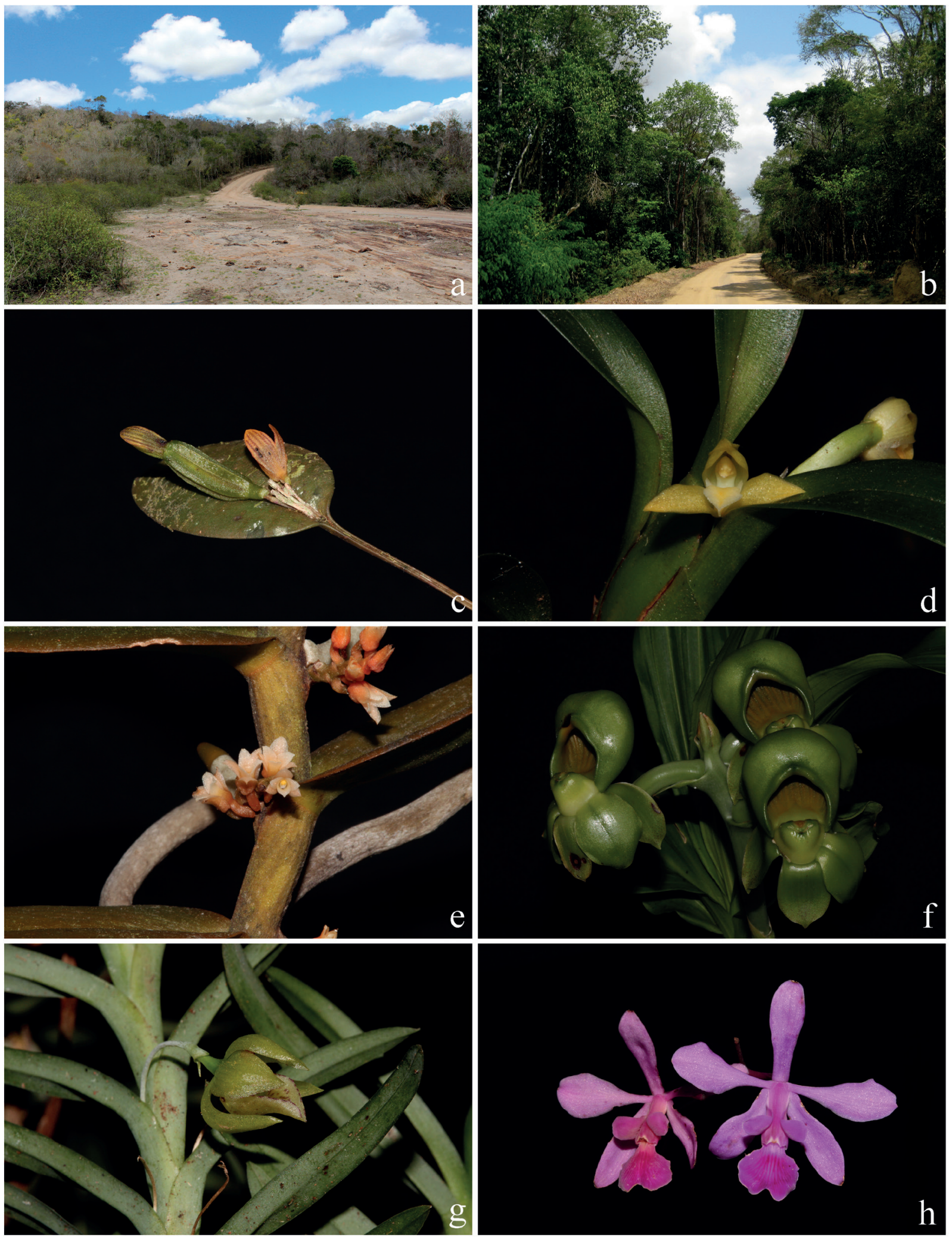

Figura 1. a-b. Vegetação de Mata de Cipó do PNBN. c. Acianthera glanduligera. d. Camaridium carinatum. e. Campylocentrum crassirhizum. f. Catasetum luridum (Flores femininas). g. Dichaea cogniauxiana. h. Encyclia ghillanyi.

Figure 1. Figure 1. a-b. Mata de Cipó Vegetation at the PNBN. c. Acianthera glanduligera. d. Camaridium carinatum. e. Campylocentrum crassirhizum. f. Catasetum luridum (Female flowers). g. Dichaea cogniauxiana. h. Encyclia ghillanyi. 
Chave taxonômica para os gêneros de Orchidaceae ocorrentes no PNBN

1. Plantas com pseudobulbos

2. Pseudobulbos sobrepostos, emergindo da base e do ápice do pseudobulbo anterior ....

27. Scaphyglottis

2. Pseudobulbos ou caule não sobrepostos, emergindo apenas da base do pseudobulbo anterior

3. Ervas com inflorescência terminal

4. Ervas terrícolas, folhas membranáceas, sépalas laterais ca. $2 \mathrm{~mm}$ compr., esverdeadas .... 15. Malaxis

4. Ervas rupícolas ou epífitas, folhas coriáceas, sépalas laterais maiores que $5 \mathrm{~mm}$ compr., flores esbranquiçadas a rosadas

5. Erva rupícola, flores ressupinadas rosadas 9. Encyclia

5. Erva epífita, flores não ressupinadas esbranquiçadas a amareladas, com estrias ou máculas vináceas

22. Prosthechea

3. Ervas com inflorescência lateral

6. Ervas terrestres ou rupícolas

7. Erva terrestre, folhas verdes com máculas, flor calcarada

18. Oeceoclades

7. Erva rupícola, folhas verdes sem máculas, flor não calcarada

8. Pseudobulbo maior que $30 \mathrm{~cm}$ compr., folhas plicadas, flores amarelas, sem máculas

8. Pseudobulbo menor que $30 \mathrm{~cm}$ compr., folhas não plicadas, flores amarelas com máculas marrons

7. Cyrtopodium

6. Ervas epífitas

9. Sépalas laterais concrescidas

10. Flores calcaradas, vermelhas a alaranjadas

6. Comparettia

10. Flores não calcaradas, esverdeadas a amareladas

11. Flores não ressupinadas, políneas 4

12. Gomesa

11. Flores ressupinadas, políneas 2

12. Folha 5,5-7 cm compr., pétalas lanceoladas

20. Polystachya

12. Folhas $9-16 \mathrm{~cm}$ compr., pétalas não lanceoladas

17. Notylia

12. Gomesa

9. Sépalas laterais livres

13. Coluna fortemente sigmoide

23. Rauhiella

13. Coluna não sigmoide

14. Pseudobulbo com ca. $18 \mathrm{~cm}$ compr., folhas plicadas, flores não ressupinadas, labelo cuculado

5. Catasetum

14. Pseudobulbo com 0,5-5 cm compr., folhas não plicadas, flores ressupinadas, labelo não cuculado

15. Erva multiflora, flores amareladas com máculas marrons

29. Trichocentrum

15. Erva uniflora, flores creme a amarelas sem máculas marrons

16. Ervas menores de $30 \mathrm{~cm}$ compr.

17. Labelo inteiro com calo ceroso

24. Rhetinantha

17. Labelo trilobado sem calo ceroso

3. Camaridium

16. Ervas maiores de $30 \mathrm{~cm}$ compr.

18. Inflorescência ca. 9,5 cm compr., flores amarelas, labelo sublobado com calo farináceo

13. Heterotaxis

18. Inflorescência ca. $19 \mathrm{~cm}$ compr., flores creme com nuances vinosoacastanhados nos ápices das sépalas e pétalas, labelo trilobado sem calo farináceo

16. Maxillaria

1. Plantas sem pseudobulbos

19. Caule unifoliado

20. Sépalas dorsal e laterais conadas

28. Stelis

20. Sépalas laterais conadas

21. Ramicaule com brácteas ciliadas

30. Trichosalpinx

21. Ramicaule sem brácteas ciliadas 
22. Inflorescência não ultrapassando o comprimento da folha

1. Acianthera

22. Inflorescência maior que a folha

23. Plantas ca. $2,5 \mathrm{~cm}$ alt., inflorescência pauciflora, sépalas não caudadas

19. Pabstiella

23. Plantas ca. $25 \mathrm{~cm}$ alt., inflorescência multiflora, sépalas caudadas

2. Anathallis

19. Caule multifoliado

24. Folhas basais em forma de roseta

25. Flor calcarada

25. Sacoila

25. Flor não calcarada

26. Flores não ressupinadas, labelo inteiro, políneas 4

21. Prescottia

26. Flores ressupinadas, labelo trilobado, políneas 2

26. Sarcoglottis

24. Folhas ao longo do caule

27. Inflorescência terminal

28. Labelo concrescido à toda extensão ventral da coluna

10. Epidendrum

28. Labelo concrescido à face lateral da coluna

11. Epistephium

27. Inflorescência lateral

29. Labelo concrescido à face lateral da coluna

31. Vanilla

29. Labelo não concrescido à face lateral da coluna

30. Inflorescência multiflora, flor calcarada 4. Campylocentrum

30. Inflorescência solitária, flor não calcarada

31. Sépalas livres

8. Dichaea

31. Sépalas conadas

14. Jacquiniella

1. Acianthera glanduligera (Lind1.) Luer, Monogr. Syst. Bot. Missouri Bot. Gard. 95: 253. 2004. $\equiv$ Pleurothallis glanduligera Lindl., Compan. Bot. Mag. 2: 355. 1836.

Figura $1 \mathrm{c}$

Erva epífita, apresenta crescimento reptante semelhante ao de outras espécies próximas, como Acianthera saundersiana (Rchb.f.) Pridgeon \& Chase, Acianthera tristes (Barb.Rodr.) Pridgeon \& Chase e Acianthera bidentula (Barb.Rodr.) Pridgeon \& Chase. Acianthera glanduligera é caracterizada por possuir flores alaranjadas com estrias vináceas, sépalas laterais conadas na base. Sépala dorsal de ápice recurvo e de tamanho maior do que as sépalas laterais. Foi coletada em flor no mês de setembro.

No Brasil ocorre na região Nordeste (BA, CE), Sudeste (ES, RJ, SP) e Sul (PR, SC) (Barros et al. 2016), não existindo ocorrência fora do território brasileiro. Na Bahia já era conhecida para a Chapada Diamantina, nos municípios de Lençóis e Palmeiras (Toscano de Brito \& Cribb 2005) e agora coletada no PNBN, na área de Mata Atlântica.

Material examinado: BRASIL. BAHIA: Boa Nova, Parque Nacional de Boa Nova, 22-IX-2012, fl, fr, C.O. Azevedo \& H.T. Rêgo 583 (HVC).

2. Anathallis sclerophylla (Lindl.) Pridgeon \& M.W.Chase, Lindleyana 16(4): 250. 2001. $\equiv$ Pleurothallis sclerophylla Lindl., Edwards's Bot. Reg. 21: sub t. 1797. 1835.
Erva epífita, inflorescência longa, multiflora. Sépalas com cerca de $1 \mathrm{~cm}$ de comprimento e sépalas e pétalas com margem inteira e pilosas. Anathallis sclerophylla é caracterizada por possuir sépalas caudadas e pétalas muito menores que as sépalas, além de apresentar labelo trilobado. Coletada em flor no mês de junho.

Espécie com distribuição dos Andes ao Sul do Brasil, chegando até o estado de Santa Catarina (Pabst \& Dungs 1975, Luer 1999, Toscano de Brito \& Cribb 2005). No Brasil ocorre nas regiões Norte (AM, RO), Nordeste (AL, BA, CE, PB, PE), Sudeste (ES, MG, RJ, SP) e Sul (PR, SC) (Barros et al. 2016). Na Bahia tinha sido coletada anteriormente na Chapada Diamantina, no município de Palmeiras (Toscano de Brito \& Cribb 2005, van den Berg \& Azevedo 2005), no Parque Nacional da Serra das Lontras, no Sul do Estado (Leitman et al. 2014) e agora encontrada no PNBN, na área de Mata Atlântica.

Material examinado: BRASIL. BAHIA: Boa Nova, Parque Nacional de Boa Nova, 15-VI-2013, fl, H.T. Rêgo 23 (HVC).

3. Camaridium carinatum (Barb.Rodr.) Hoehne, Arq. Bot. Estado São Paulo n.s., form. maior, 2: 72. 1947. $\equiv$ Maxillaria carinata Barb.Rodr., Gen. Sp. Orchid. 2: 210.1882.

Figura $1 \mathrm{~d}$

Camaridium carinatum é uma espécie epífita com inflorescência de cerca de 3 a $4 \mathrm{~cm}$ de comprimento. 
Possui flores amarelas, brácteas recobrindo o ovário e labelo trilobado. Coletada em flor no mês de setembro.

Esta espécie ocorre na Bolívia, Brasil, Colômbia, Equador, Guiana, Peru, Suriname e Venezuela (Blanco 2008). No Brasil ocorre nas regiões Nordeste (BA, CE, PE), Sudeste (ES, MG, RJ, SP), e Sul (PR e SC) (Barros et al. 2016). Na Bahia foi citada para a Serra das Lontras (Leitman et al. 2014) e no PNBN foi encontrada na área de Mata Atlântica.

Material examinado: BRASIL. BAHIA: Boa Nova, Parque Nacional de Boa Nova, 22-IX-2012, fl, C.O. Azevedo \& H.T. Rêgo 580 (HVC).

\section{Campylocentrum Benth.}

Chave taxonômica para as espécies de Campylocentrum do PNBN

1. Folha oblonga ..... 4.1. Campylocentrum crassirhizum 1. Folha aciculada ......... 4.2. Campylocentrum sellowii

4.1. Campylocentrum crassirhizum Hoehne, Arq.

Bot. Estado São Paulo 1: 44. 1939.

Figura $1 \mathrm{e}$

Campylocentrum crassirhizum é uma espécie epífita, com folhas oblongas e flores ressupinadas, de coloração esbranquiçada e labelo trilobado. Floresce de novembro a abril.

Espécie endêmica do Brasil ocorre nas regiões Nordeste (AL, BA, CE, PB, PE, RN, SE), Centro-Oeste (MS), Sudeste (ES, MG, RJ, SP) e Sul (PR, SC) (Barros et al. 2016). No PNBN foi coletada na área de Mata de Cipó.

O CNCFlora avaliou esta espécie quanto ao Status de conservação como LC (pouco preocupante).

Material examinado: BRASIL. BAHIA: Boa Nova, Parque Nacional de Boa Nova, 10-IV-2013, fl, C.O. Azevedo \& H.T. Rêgo 648 (HVC).

4.2. Campylocentrum sellowii (Rchb.f.) Rolfe, Orchid Rev.11:246. 1903. 三Angraecum sellowii Rchb. f., Linnaea22:857.1849. = Campylocentrumaciculatum (Rchb.f. \& Warm.) Cogn., Fl. Bras. (Martius) 3(6): 516. 1906. = Aeranthes aciculata Rchb.f. \& Warm., Otia Bot. Hamburg. 91. 1881.

Campylocentrum selowii é caracterizada pelas plantas robustas com folhas aciculares, com cerca de $2-5 \mathrm{~cm}$ de comprimento, espessas, de coloração verde a acastanhada. Possui flores esbranquiçadas, diminutas, sépalas com cerca de 1,5 a $2 \mathrm{~mm}$ de comprimento e labelo inteiro. Coletada em flor no mês de março.
De distribuição restrita ao Brasil, foi citada para todos os estados da região Sudeste e no Nordeste somente para a Bahia (Barros et al. 2016). Na Bahia já foi citada para Catolés (Toscano de Brito \& Queiroz 2003) e Morro do Chapéu (Bastos \& van den Berg 2012a), identificada como Campylocentrum aciculatum. No PNBN foi coletada na área de Mata de Cipó.

Material examinado: BRASIL. BAHIA: Boa Nova, Parque Nacional de Boa Nova, 30-III-2014, fl, H.T. Rêgo 34 (HVC).

5. Catasetum luridum Lindl., Gen. Sp. Orchid. P1. 156. 1832.

Figura $1 \mathrm{f}$

Catasetum luridum cresce quase que exclusivamente como epífita sobre Licuri (Syagrus coronata (Mart.) Becc.) (Bastos \& van den Berg 2012b). Esta possui flor ressupinada com labelo arredondado e margens inteiras. Coletada em flor no mês de janeiro.

Endêmica do Brasil ocorre nas regiões Nordeste (BA) e Sudeste (ES, RJ) (Barros et al. 2014). No PNBN foi coletada na área de Mata de Cipó.

Esta espécie não foi avaliada quanto ao status de conservação pelo CNCFlora. Contudo, é uma espécie comum na Caatinga, bem coletada nos municípios do Estado da Bahia.

Material examinado: BRASIL. BAHIA: Boa Nova, Parque Nacional de Boa Nova, 23-I-2013, fl, H.T. Rêgo 16 (HVC).

6. Comparettia coccinea Lindl., Sketch Veg. Swan R. 24: t. 68. 1838.

Comparettia coccinea é uma espécie epífita com inflorescência em racemo lateral. As flores são calcaradas, de coloração avermelhada a alaranjada. Possui labelo trilobado, com dois calos entre os lobos laterais. Coletada em flor no mês de junho.

Endêmica do Brasil ocorre nas regiões Nordeste (BA, PE), Centro-Oeste (DF) e Sudeste (MG, SP) (Barros et al. 2016). Durante o desenvolvimento deste trabalho foi coletada na área de Mata Atlântica do PNBN.

Material examinado: BRASIL. BAhIA: Boa Nova, Parque Nacional de Boa Nova, 15-VI-2013, fl, H.T. Rêgo 21 (HVC).

7. Cyrtopodium flavum Link \& Otto ex Rchb., Iconogr. Bot. Exot. 3: 7, t. 214. 1830.

Cyrtopodium flavum é uma espécie rupícola ou terrícola com flores ressupinadas, amarelas e possui 
labelo trilobado. Floresce entre os meses de novembro a janeiro.

Endêmica do Brasil ocorre nas regiões Nordeste (AL, BA, PB, PE, SE), Sudeste (ES, MG, RJ, SP) e Sul (PR, RS, SC) (Barros et al. 2016). Na Bahia já foi encontrada em Lençóis (Toscano de Brito 1998) e Mucugê (Azevedo \& van den Berg 2007), identificada como Cyrtopodium polyphyllum (Vell.) Pabst ex F. Barros, em Morro do Chapéu (Bastos \& van den Berg 2012a) e agora no PNBN, nas áreas de Mata de Cipó e Mata Atlântica.

O CNCFlora avaliou esta espécie quanto ao status de conservação como LC (pouco preocupante).

Material examinado: BRASIL. BAHIA: Boa Nova, Parque Nacional de Boa Nova, 24-XI-2012, fl, H.T. Rêgo 07 (HVC); 25-I-2012, fl, H.T. Rêgo 11 (HVC).

8. Dichaea cogniauxiana Schltr., Anexos Mem. Inst. Butantan, Secc. Bot. 1(4): 66. 1922.

Figura $1 \mathrm{~g}$

Dichaea cogniauxiana é uma planta epífita, apresenta flores esverdeadas, labelo em forma de âncora com máculas vináceas. É reconhecida por possuir folhas caducas, articuladas com a bainha e ovário glabro. Coletada em flor no mês de agosto e novembro.

Espécie endêmica do Brasil ocorre nas regiões Norte (AM, PA), Nordeste (BA, PB, SE), CentroOeste (MT), Sudeste (ES, MG, RJ, SP) e Sul (PR, SC) (Barros et al. 2016). Na Bahia já foi citada para alguns municípios da Chapada Diamantina: Abaíra, Lençóis e Palmeiras (Toscano de Brito \& Cribb 2005, van den Berg \& Azevedo 2005), e para a Serra das Lontras, no Sul do Estado (Leitman et al. 2014). No PNBN foi coletada na área de Mata Atlântica.

Material examinado: BRASIL. BAHIA: Boa Nova, Parque Nacional de Boa Nova, 22-XI-2013, fl, C.O. Azevedo \& H.T. Rêgo 674 (HVC); 17-VIII-2013, fl, fr, H.T. Rêgo 31 (HVC).

\section{Encyclia ghillanyi Pabst, Bradea 2: 80. 1976.}

Figura $1 \mathrm{~h}$

Erva rupícola, apresenta flores rosadas. Encyclia dichroma e E. ghillanyi são espécies muito parecidas e frequentemente confundidas. Análises genéticas sugerem uma recente especiação (Almeida et al. 2009). Encyclia dichroma ocorre em áreas de baixas altitudes, nas restingas e dunas do litoral da Bahia, enquanto E. ghillanyi habita ambientes de altitudes maiores no interior da Bahia (Almeida et al. 2009). Foi coletada em flor nos meses de setembro e fevereiro.
É endêmica do interior da Bahia (Barros et al. 2016). No PNBN foi coletada em área de Mata de Cipó, em região de afloramento rochoso.

Material examinado: BRASIL. BAHIA: Boa Nova, Parque Nacional de Boa Nova, 21-IX-2012, fl, C.O. Azevedo \& H.T. Rêgo 525 (HVC); 24-II-2013, fl, L.C. Marinho 410 (HVC).

\section{Epidendrum L.}

Chave taxonômica das espécies de Epidendrum do PNBN

1. Ervas epífitas, flores ressupinadas

2. Inflorescência pluriflora

2. Inflorescência uniflora

10.4. Epidendrum strobiliferum

10.1. Epidendrum carpophorum

1. Ervas rupícolas, flores não-ressupinadas

3. Labelo 1,7-2 cm compr., amarelo e rosa, máculas rosadas ... 10.2. Epidendrum cinnabarinum

3. Labelo 0,6-0,8 cm compr., rosa, calos brancos com nuances amarelos ... 10.3. Epidendrum secundum

10.1. Epidendrum carpophorum Barb.Rodr., Gen. Sp. Orchid. 2: 148. 1882.

Epidendrum carpophorum é epífita e possui flores esbranquiçadas, sépalas e pétalas lanceoladas e labelo trilobado. Em alguns indivíduos as flores não se abrem, ou seja, são cleistógamas. Foi coletada em flor no mês de setembro.

No Brasil ocorre nas regiões Norte (AM, AP, PA, RR), Nordeste (AL, BA, CE, PE, SE) e Sudeste (ES, MG, RJ, SP) (Barros et al. 2016). Na Bahia já foi citada para a Chapada Diamantina, para os municípios de Lençóis e Palmeiras (Toscano de Brito \& Cribb 2005, van den Berg \& Azevedo 2005), e durante o desenvolvimento deste trabalho coletada na área de Mata Atlântica do PNBN.

O CNCFlora avaliou esta espécie quanto ao status de conservação como LC (pouco preocupante).

Material examinado: BRASIL. BAHIA: Boa Nova, Parque Nacional de Boa Nova, 22-IX-2012, fl, fr, C.O. Azevedo \& H.T. Rêgo 587 (HVC).

10.2. Epidendrum cinnabarinum Salzm. ex Lindl.,

Bot. Mus. Leafl.106. 1831.

Figura 2 a

Epidendrum cinnabarinum é uma espécie rupícola ou terrícola, com flores não ressupinadas, alaranjada a rosada com labelo amarelado e com pequenas máculas rosadas. Possui labelo trilobado 

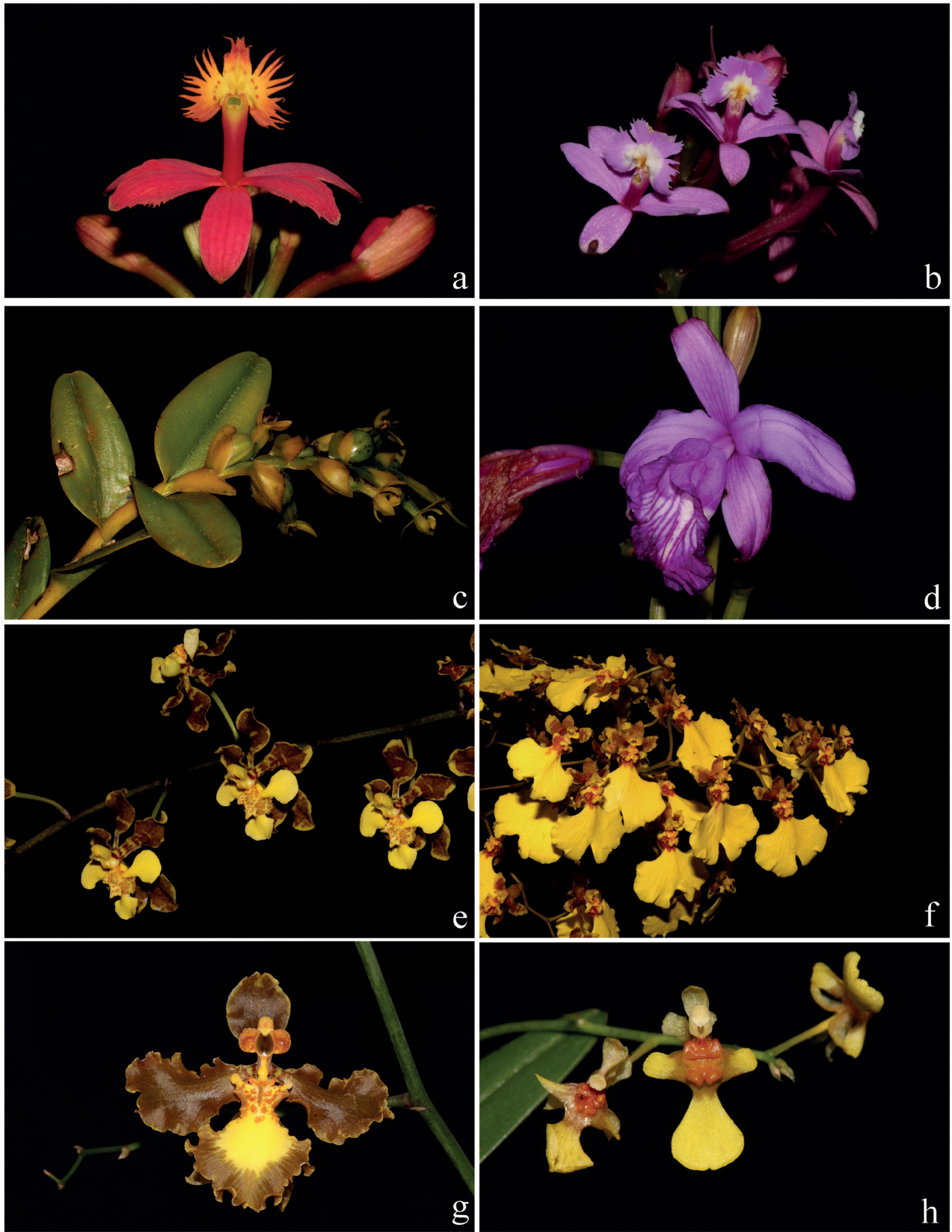

Figura 2. a. Epidendrum cinnabarinum. b. Epidendrum secundum. c. Epidendrum strobiliferum. d. Epistephium lucidum. e. Gomesa ciliata. f. Gomesa flexuosa. g. Gomesa gravesiana. h. Gomesa hookeri.

Figure 2. a. Epidendrum cinnabarinum. b. Epidendrum secundum. c. Epidendrum strobiliferum. d. Epistephium lucidum. e. Gomesa ciliata. f. Gomesa flexuosa. g. Gomesa gravesiana. h. Gomesa hookeri. 
com dois calos lineares. Foi coletada em flor no mês de novembro.

No Brasil ocorre na região Nordeste (AL, BA, PB, $\mathrm{PE}, \mathrm{RN}, \mathrm{SE}$ ) e no Estado do Espírito Santo (Barros et al. 2016). Na Bahia já foi citada para o município de Morro do Chapéu (Bastos \& van den Berg 2012a) e agora coletada no PNBN, na área de Mata de Cipó.

Material examinado: BRASIL. BAHIA: Boa Nova, Parque Nacional de Boa Nova, 25-XI-2012, fl, H.T. Rêgo 10 (HVC).

10.3. Epidendrum secundum Jacq., Enum. Syst. P1. 29. 1760.

Figura $2 \mathrm{~b}$

Epidendrum secundum é uma espécie rupícola ou terrícola, caracteriza-se por possuir flores rosadas e labelo com calos brancos com nuances amarelas. Foi coletada em flor nos meses de setembro e outubro.

Trata-se de uma espécie com ampla distribuição pelo continente americano, podendo ser encontrada desde a Flórida até o Rio Grande do Sul (Pabst \& Dungs 1975, Pinheiro 2005, Toscano de Brito \& Cribb 2005). No Brasil ocorre no Norte (AM, AP, PA, RR, TO), Nordeste (AL, BA, CE, PB, PE, SE), Centro-Oeste (DF, GO, MT), Sudeste (ES, MG, RJ, SP) e Sul (PR, RS, SC) (Barros et al. 2016). Na Bahia já foi citada para Santa Terezinha (Queiroz et al. 1996), e na Chapada Diamantina para o Pico das Almas (Toscano de Brito 1995), Palmeiras (Toscano de Brito 1998), Mucugê (Azevedo \& van den Berg 2007a), Morro do Chapéu (Bastos \& van den Berg 2012a) e Lençóis (Toscano de Brito \& Cribb 2005) e no Sul do estado para a Serra das Lontras (Leitman et al. 2014) e agora registrada para as áreas de Mata de Cipó e Mata Atlântica do PNBN.

O CNCFlora avaliou esta espécie quanto ao status de conservação como LC (pouco preocupante).

Material examinado: BRASIL. BAHIA: Boa Nova, Parque Nacional de Boa Nova, 21-IX-2012, fl, C.O. Azevedo \& H.T. Rêgo 526 (HVC); 26-X-2012, fl, H.T. Rêgo 1 (HVC).

10.4. Epidendrum strobiliferum Rchb.f., Ned. Kruidk. Arch. 4: 333. 1859.

Figura $2 \mathrm{c}$

Epidendrum strobiliferum é uma espécie rupícola de habito pendente. Epidendrum strobiliferum e E. rodriguesii Cogn. apresentam características vegetativas e flores muito semelhantes, sendo que a principal diferença é o labelo, que em $E$. strobiliferum é inteiro e em $E$. rodriguesii é trilobado. Foi coletada em fruto no mês de março.
No Brasil está presente nas regiões Norte (AC, AM, AP, PA, RR), Nordeste (AL, BA, CE, MA, PE, $\mathrm{SE})$, Centro-Oeste (GO, MT), e em todos os Estados da região Sudeste e Sul (Barros et al. 2016). No PNBN foi coletada em área de Mata Atlântica.

Material examinado: BRASIL. BAHIA: Boa Nova, Parque Nacional de Boa Nova, 22-III-2013, fr, C.O. Azevedo et al. 636 (HVC).

11. Epistephium lucidum Cogn., Fl. Bras. 3(4): 141, t. 30.1893.

Figura $2 \mathrm{~d}$

Epistephium lucidum é uma espécie terrícola com flores ressupinadas, rosas a lilás. Se caracteriza pelo labelo conado à face lateral da coluna. O labelo apresenta tricomas em todo o comprimento da porção central e apresenta margem ondulada. Foi coletada florida no mês de março.

Endêmica do Brasil ocorre nas regiões Norte (RR, TO), Nordeste (BA, PB, PE, SE), Centro-Oeste (DF, GO, MS) e em todos os Estados da região Sudeste (Barros et al. 2016). Na Bahia já foi encontrada em Catolés (Toscano de Brito \& Queiroz 2003), Morro do Chapéu (Bastos \& van den Berg 2012a), Mucugê (Azevedo \& van den Berg 2007a), Pico das Almas (Toscano de Brito 1995) e em Santa Terezinha (Queiroz et al. 1996). Durante o desenvolvimento deste trabalho foi coletada no PNBN em área de Mata Atlântica.

Material examinado: BRASIL. BAHIA: Boa Nova, Parque Nacional de Boa Nova, 22-III-2013, fl, C.O. Azevedo et al. 634 (HVC).

\section{Gomesa Lodd.}

Chave taxonômica para as espécies de Gomesa do PNBN

1. Erva 70-80 cm compr. incluindo a inflorescência

2. Sépalas e pétalas marrons com bordas onduladas amarelas ... 12.3. Gomesa gravesiana

2. Sépalas e pétalas amarelas com máculas marrons sem bordas onduladas 12.2. Gomesa flexuosa

1. Erva $15-42 \mathrm{~cm}$ compr. incluindo a inflorescência

3. Flores esverdeadas, sépalas e pétalas maiores que o labelo, labelo genuflexo 12.5. Gomesa recurva

3. Flores amarelas a amarelo-limão, sépalas e pétalas menores que o labelo, labelo não genuflexo 
4. Sépalas ca. 2,5 cm compr., labelo ciliado com lobos laterais maiores que o lobo central 12.1. Gomesa ciliata

4. Sépalas ca. 0,6 cm compr., labelo não ciliado com lobos laterais menores que o lobo central .... 12.4. Gomesa hookeri

12.1. Gomesa ciliata (Lind1.) M.W.Chase \& N.H.Williams, Ann. Bot. (Oxford) 104(3): 396. 2009. Oncidium ciliatum Lindl., Gen. Sp. Orchid. P1. 200. 1833.

Figura $2 \mathrm{e}$

Gomesa ciliata é uma espécie epífita com sépalas e pétalas amarelas maculadas de castanho, apresenta sépalas laterais conadas na base e labelo amarelo, trilobado e ciliado. Floresce entre os meses de fevereiro e março.

Espécie endêmica do Brasil ocorre nas regiões Nordeste (BA, CE) e em todos os Estados das regiões Sudeste e Sul (Barros et al. 2016). Durante o desenvolvimento deste trabalho foi coletada nas áreas de Mata de Cipó e Mata Atlântica do PNBN.

Material examinado: BRASIL. BAHIA: Boa Nova, Parque Nacional de Boa Nova, 23-III-2013, fl, C.O. Azevedo \& H.T. Rêgo 638 (HVC).

\subsection{Gomesa flexuosa (Lodd.) M.W.Chase \&}

N.H.Williams, Phytotaxa 1: 58. 2009. $\equiv$ Oncidium

flexuosum Lodd., Bot. Cab. 5: t. 424. 1820.

Figura $2 \mathrm{f}$

Gomesa flexuosa é uma espécie epífita, terrícola ou rupícola. Apresenta sépalas laterais conadas na base, de coloração amarela, com máculas marrons e calo na região basal com inúmeras papilas diminutas densamente agrupadas. Foi coletada em flor no mês de setembro.

A espécie possui ampla distribuição pelo território brasileiro e na Argentina (Pabst \& Dungs 1977). No Brasil ocorre nos Estados das regiões Norte (PA), Nordeste (BA, PB, PE) e em todos os estados das regiões Sudeste e Sul. Na Bahia foi encontrada em Santa Terezinha (Queiroz et al. 1996), Lençóis (Toscano de Brito \& Cribb 2005) e no Sul do Estado para a Serra das Lontras (Leitman et al. 2014). No PNBN foi coletada na área de Mata de Cipó e Mata Atlântica.

Material examinado: BRASIL. BAHIA: Boa Nova, Parque Nacional de Boa Nova, 21-IX-2012, fl, C.O. Azevedo \& H.T. Rêgo 528 (HVC).
12.3. Gomesa gravesiana (Rolfe) M.W.Chase \& N.H. Williams, Ann. Bot. (Oxford) 104(3): 397. 2009. $\equiv$ Oncidium gravesianum Rolfe, Gard. Chron. ser. 3, 11: 650, f. 94.1892

Figura $2 \mathrm{~g}$

Espécie epífita, flores com sépalas e pétalas marrons com bordas amarelas e labelo amarelo com margem castanha. O labelo é trilobado e apresenta margem ondulada. Foi coletada em flor no mês de fevereiro.

Endêmica do Brasil ocorre nas regiões Nordeste (BA, PB, PE) e em todos os Estados das regiões Sudeste e Sul (Barros et al. 2016). Na Bahia já foi citada para a Chapada Diamantina nos municípios de Morro do Chapéu, Abaíra e Rio de Contas (Bastos \& van den Berg 2012a, Toscano de Brito \& Cribb 2005, van den Berg \& Azevedo 2005) e durante este estudo coletada no PNBN na área de Mata de Cipó.

O CNCFlora avaliou esta espécie quanto ao status de conservação como LC (pouco preocupante).

Material examinado: BRASIL. BAHIA: Boa Nova, Parque Nacional de Boa Nova, 24-II-2013, fl, L.C. Marinho 411 (HVC).

12.4. Gomesa hookeri (Rolfe) M.W.Chase \& N.H. Williams, Ann. Bot. (Oxford) 104(3): 397. 2009. $\equiv$ Oncidium hookeri Rolfe, Gard. Chron. ser. 3, 2: 520.1887.

Figura $2 \mathrm{~h}$

Gomesa hookeri é uma erva epífita. Possui inflorescência em panícula, flores amarelas com sépalas laterais conadas na base. O labelo é amarelo e apresenta uma calosidade marrom na região basal. Das espécies de Gomesa que ocorrem na região estudada esta é a que possui flores menores, com sépalas com cerca de $0,6 \mathrm{~cm}$ de comprimento. Apresenta grande variação morfológica, o que tem causado uma série de confusões nomenclaturais. Foi coletada em flor no mês de outubro.

Endêmica do Brasil, já foi coletada em todos os estados das regiões Sudeste e Sul, e na região Nordeste é conhecida para a Bahia e Pernambuco. Na Bahia foi citada para a Chapada Diamantina nos municípios de Morro do Chapéu (Bastos \& van den Berg 2012a), Lençóis e Palmeiras (Toscano de Brito \& Cribb 2005), e para a Serra das Lontras, no Sul do Estado (Leitman et al. 2014). No PNBN foi coletada na área de Mata Atlântica.

Material examinado: BRASIL. BAHIA: Boa Nova, Parque Nacional de Boa Nova, 27-X-2013, fl, C.O. Azevedo \& H.T. Rêgo 672 (HVC). 
12.5. Gomesa recurva R.Br., Bot. Mag. 42: t. 1748. 1815.

Figura 3 a

Gomesa recurva é uma espécie epífita com inflorescência em racemo, pendente, apresenta flores esverdeadas e labelo genuflexo, com duas alas laterais e dois calos centrais claviformes. Foi coletada em flor no mês de julho.

No Brasil ocorre em todos os Estados das regiões Sudeste e Sul e no estado da Bahia (Barros et al. 2016), onde foi registrada para a Serra das Lontras (Leitman et al. 2014). No PNBN foi coletada na área de Mata Atlântica.

Material examinado: BRASIL. BAHIA: Boa Nova, Parque Nacional de Boa Nova, 21-XII-2012, fl, H.T. Rêgo 15 (HVC).

13. Heterotaxis sessilis (Sw.) F. Barros, Hoehnea 29(2): 112. 2002. E Epidendrum sessile Sw., Prodr. 122. 1788.

Figura $3 \mathrm{~b}$

Espécie de Maxillariinae de médio a grande porte, pode passar de $40 \mathrm{~cm}$ de altura. É uma erva epífita, os pseudobulbos são unifoliados e comprimidos, com folhas sulcadas na base. A inflorescência é curta e surge da axila das folhas, com cerca de 4 ou $5 \mathrm{~cm}$ de comprimento. Possui flor isolada, amarela e labelo amarelo com máculas vermelhas. O labelo possui calo farináceo característico da espécie. Foi coletada em flor no mês de maio.

No Brasil ocorre em todos os Estados da região Sudeste, na região Norte apenas no Amazonas e Pará, e no Nordeste é conhecida apenas para a Bahia (Barros et al. 2016). No PNBN foi coletada na área de Mata Atlântica.

O CNCFlora avaliou esta espécie quanto ao status de conservação como LC (pouco preocupante).

Material examinado: BRASIL. BAHIA: Boa Nova, Parque Nacional de Boa Nova, 23-V-2014, fl, C.O. Azevedo \& H.T. Rêgo 675 (HVC).

14. Jacquiniella globosa (Jacq.) Schltr, Repert. Spec. Nov. Regni Veg. Beih. 7: 124. 1920. EEpidendrum globosum Jacq., Enum. Syst. P1. 29. 1760.

Figura $3 \mathrm{c}$

Jacquiniella globosa é uma espécie epífita de porte pequeno. Possui folhas de filotaxia alterna dística, esparsas ao longo de todo o caule. Apresenta flores solitárias, de coloração esbranquiçada e a coluna parcialmente conada ao labelo. Foi coletada em flor no mês de setembro.

Espécie amplamente distribuída por toda a América do Sul, alcançando a América Central e o México (Pabst \& Dungs 1975). É encontrada, mais comumente, associada à Mata Atlântica (Romanini 2006). No Brasil ocorre nas regiões Norte (AM, PA, RR), Nordeste (AL, BA, CE, PE, SE), Sudeste (ES, RJ, SP) e Sul (PR, SC) (Barros et al. 2016). Na Bahia foi citada para a Serra das Lontras (Leitman et al. 2014). No PNBN foi coletada na área de Mata Atlântica.

O CNCFlora avaliou esta espécie quanto ao status de conservação como LC (pouco preocupante).

Material examinado: BRASIL. BAHIA: Boa Nova, Parque Nacional de Boa Nova, 22-IX-2012, fl, C.O. Azevedo \& H.T. Rêgo 582 (HVC).

15. Malaxis parthonii C.Morren, Bull. Acad. Roy.

Sci. Bruxelles 5: 485, t. 1838. 1839.

Figura $3 \mathrm{~d}$

Malaxis parthonii é uma espécie terrícola, apresenta sépalas laterais com cerca de $2 \mathrm{~mm}$ de comprimento. As flores são verdes e possuem pétalas lineares, reflexas. Foi coletada em flor no mês de junho.

No Brasil ocorre nas regiões Nordeste (CE), Sudeste (MG, RJ, SP) e Sul (PR, RS, SC) (Barros et al. 2016). Sendo aqui coletada pela primeira vez na Bahia, no município de Boa Nova, em área de Mata de Cipó.

O CNCFlora avaliou esta espécie quanto ao status de conservação como LC (pouco preocupante).

Material examinado: BRASIL. BAHIA: Boa Nova, Parque Nacional de Boa Nova, 16-VI-2013, fl, H.T. Rêgo 24 (HVC).

16. Maxillaria leucaimata Barb. Rodr., Gen. Sp. Orchid. 2: 198. 1881.

Figura 3 e

Maxillaria leucaimata é uma espécie epífita, caracterizada pela inflorescência muito mais longa que o pseudobulbo, e por apresentar flores creme com nuances vináceo nos ápices das sépalas e pétalas. Foi coletada em flor no mês de novembro.

No Brasil ocorre nas regiões Norte (AM, PA), Nordeste (BA, CE, PE), Sudeste (ES, MG, RJ, $\mathrm{SP})$ e Sul (PR, SC) (Barros et al. 2016). Foi citada recentemente para a Serra das Lontras, no Sul da Bahia (Leitman et al. 2014). No PNBN foi coletada na área de Mata Atlântica. 

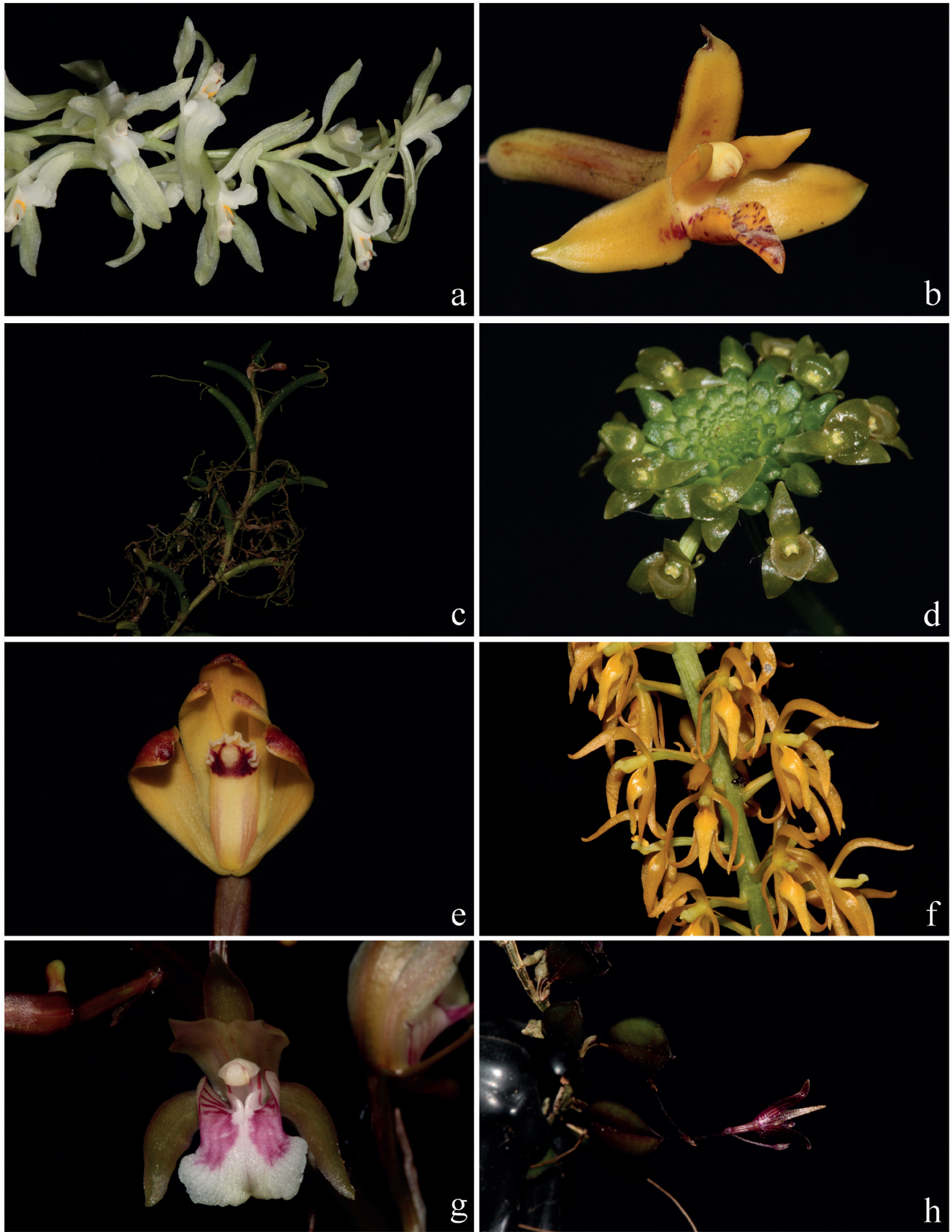

Figura 3. a. Gomesa recurva. b. Heterotaxis sessilis. c. Jacquiniella globosa. d. Malaxis parthonii. e. Maxillaria leucaimata. f. Notylia pubescens. g. Oeceoclades maculata. h. Pabstiella brasilica.

Figure 3. a. Gomesa recurva. b. Heterotaxis sessilis. c. Jacquiniella globosa. d. Malaxis parthonii. e. Maxillaria leucaimata. f. Notylia pubescens. g. Oeceoclades maculata. h. Pabstiella brasilica. 
Material examinado: BRASIL. BAHIA: Boa Nova, Parque Nacional de Boa Nova, 24-XI-2012, fl, H.T. Rêgo 8 (HVC).

17. Notylia pubescens Lindl., Edwards's Bot. Reg. 28 (Misc.): 62.1842.

\section{Figura $3 \mathrm{f}$}

Erva epífita, possui inflorescência pendente com cerca de 100 flores diminutas, com aproximadamente $4 \mathrm{~mm}$ de diâmetro. As flores têm coloração amareloesverdeada a amarelo-alaranjada. As sépalas laterais são concrescidas na base até cerca de $1 / 3$ do comprimento. Foi coletada em flor nos meses de setembro a dezembro.

Notylia pubescens foi citada para o Nordeste (BA, CE), Sudeste (ES, MG, RJ) e Sul do país (PR, RS, SC) (Barros et al. 2016). Na Bahia ocorre na Chapada Diamantina nos municípios de Morro do Chapéu (Bastos \& van den Berg 2012a), Rio de Contas (Toscano de Brito \& Cribb 2005) e durante as excursões de coleta deste trabalho foi coletada no PNBN em área de Mata de Cipó.

Material examinado: BRASIL. BAHIA: Boa Nova, Parque Nacional de Boa Nova, 21-IX-2012, fl, C.O. Azevedo \& H.T. Rêgo 524 (HVC); 26-X-2013, fl, C.O. Azevedo \& H.T. Rêgo 670 (HVC); 22-XII-2012, fl, H.T. Rêgo 13 (HVC).

18. Oeceoclades maculata (Lindl.) Lindl., Gen. Sp. Orchid. Pl. 237-238. 1833. EAngraecum maculatum Lindl., Coll. Bot. 3: pl. 15. 1821.

Figura $3 \mathrm{~g}$

Oeceoclades maculata é uma espécie terrícola, caracterizada por apresentar folhas verdes com máculas verde-escuro. As flores são arroxeadas, o labelo é branco com máculas rosa, suas flores possuem calcar e o labelo é trilobado. Na região de estudo foi encontrada em flor entre fevereiro e maio.

Distribuída amplamente na África, e da América do Norte até a Argentina (Pabst \& Dungs 1977). No Brasil foi citada para todos os Estados brasileiros (Barros et al. 2016). Na Bahia já foi citada para Vitória da Conquista (Marinho \& Azevedo 2013) e na Chapada Diamantina para os municípios de Abaíra, Jacobina, Morro do Chapéu, Palmeiras e Rio de Contas (Bastos \& van den Berg 2012a, Toscano de Brito \& Cribb 2005, van den Berg \& Azevedo 2005). Durante o desenvolvimento deste projeto foi coletada nas áreas de Mata de Cipó e Mata Atlântica do PNBN.

Esta espécie não foi avaliada quanto ao status de conservação pelo CNCFlora. Contudo é uma espécie exótica que ocorre em todo o território brasileiro.
Material examinado: BRASIL. BAHIA: Boa Nova, Parque Nacional de Boa Nova, 23-III-2013, fl, C.O. Azevedo et al. 639 (HVC); 24-V-2013, fl, H.T. Rêgo 20 (HVC); 24-II-2013, fl, fr, L.C. Marinho 401 (HVC).

19. Pabstiella brasilica Luer \& Toscano, Harvard Pap. Bot. 17(2): 310. 2012.

Figura 3 h-4 a

Pabstiella brasilica é uma espécie epífita, caracterizada por apresentar folhas vináceas com cerca de $0,9 \mathrm{~mm}$ de comprimento. Suas flores, também diminutas, apresentam coloração vinácea e possuem sépalas laterais conadas e labelo lobado. Foi coletada em flor no mês de setembro.

A espécie endêmica da Bahia, até o momento só tinha sido registrada para a localidade tipo, município de Lucaia (Luer \& Toscano 2012), e durante o desenvolvimento deste projeto foi encontrada na área de Mata de Cipó no PNBN.

Esta espécie não foi avaliada quanto ao status de conservação pelo CNCFlora, contudo é uma espécie aparentemente rara. Até o momento só era conhecida da localidade tipo, área que vem sofrendo grande pressão antrópica.

Material examinado: BRASIL. BAHIA: Boa Nova, Parque Nacional de Boa Nova, 22-IX-2012, fl, C.O. Azevedo \& H.T. Rêgo 589 (HVC).

20. Polystachya estrellensis Rchb.f., Linnaea 25: 231. 1852.

Erva epífita, de flores não-ressupinadas, de coloração esverdeada. Possui labelo trilobado, oblongo e lobo terminal com margem inteira. Foi coletada em flor no mês de março.

Polystachya estrellensis distribui-se pelo Paraguai e por todo o Brasil, principalmente em regiões litorâneas (Pabst \& Dungs 1975, Barros et al. 2016). Na Bahia foi encontrada em Morro do Chapéu (Bastos \& van den Berg 2012a) e na Serra das Lontras (Leitman et al. 2014). No Sudoeste do Estado foi citada para o município de Vitória da Conquista (Marinho \& Azevedo 2013), e durante este projeto coletada na área de Mata Atlântica do PNBN.

Material examinado: BRASIL. BAHIA: Boa Nova, Parque Nacional de Boa Nova, 22-III-2013, fl, C.O. Azevedo \& H.T. Rêgo 637 (HVC).

21. Prescottia plantaginifolia Lindl. ex Hook., Exot. Fl. 2: t. 115. 1824.

Figura $4 \mathrm{~b}$ 

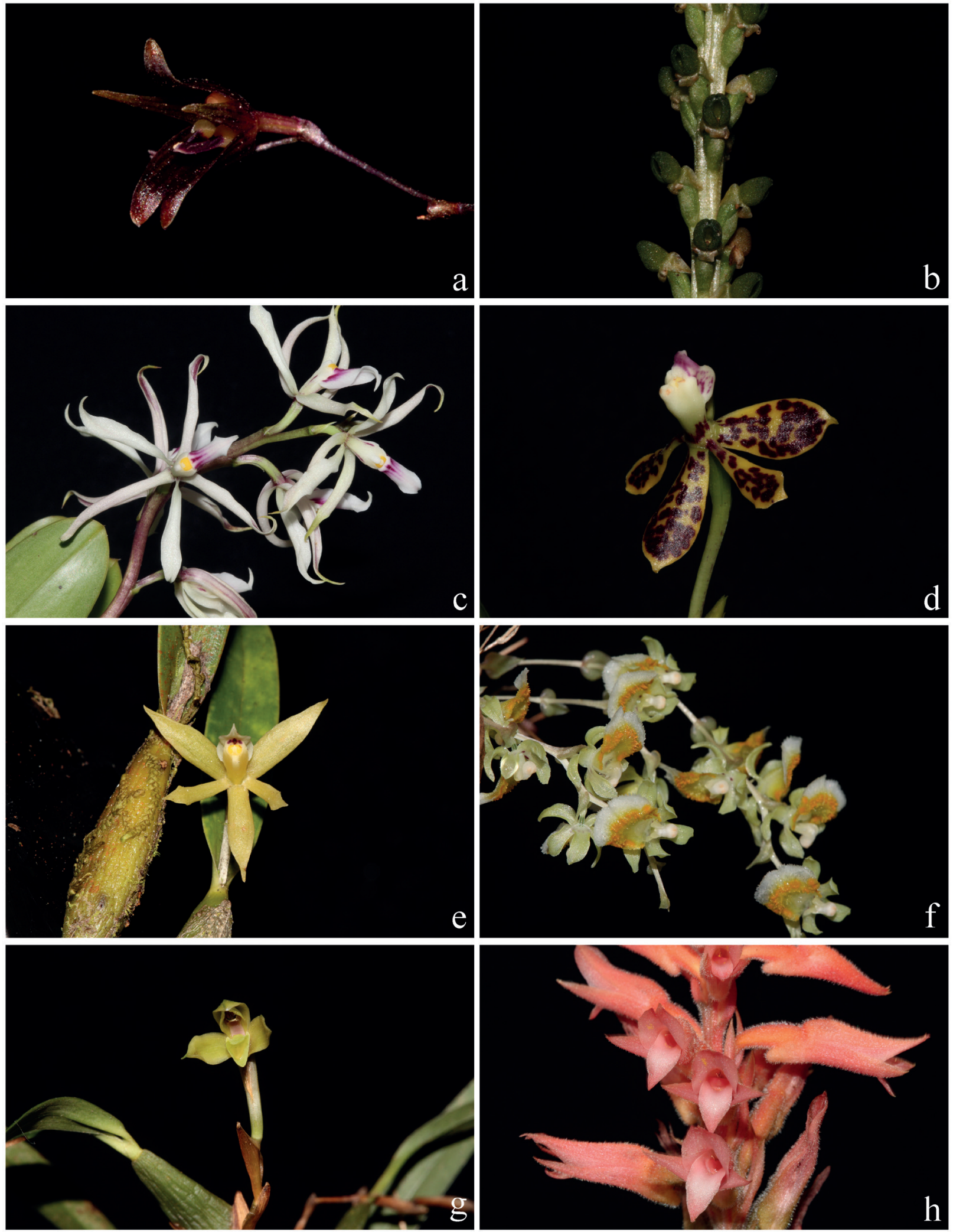

Figura 4. a. Pabstiella brasilica. b. Prescottia plantaginifolia. c. Prosthechea allemanoides. d. Prosthechea pachysepala. e. Prosthechea pygmaea. f. Rauhiella silvana. g. Rhetinantha notylioglossa. h. Sacoila lanceolata.

Figure 4. Figure 4. a. Pabstiella brasilica. b. Prescottia plantaginifolia. c. Prosthechea allemanoides. d. Prosthechea pachysepala. e. Prosthechea pygmaea. f. Rauhiella silvana. g. Rhetinantha notylioglossa. h. Sacoila lanceolata. 
Prescottia plantaginifolia é uma espécie terrícola com folhas não pecioladas. Possuem flores verdes, não ressupinadas, com labelo cuculado e quatro políneas. Foi coletada em flor nos meses de agosto e setembro.

Espécie endêmica do Brasil ocorre nos Estados do Nordeste (AL, BA, PB, PE, RN, SE), Centro-Oeste (GO), Sudeste (ES, MG, RJ, SP) e Sul (PR, SC) (Barros et al. 2016). No PNBN foi encontrada na área de Mata de Cipó e Mata Atlântica.

Material examinado: BRASIL. BAHIA: Boa Nova, Parque Nacional de Boa Nova, 21-IX-2012, fl, C.O. Azevedo \& H.T. Rêgo 527 (HVC); 27-VIII-2013, fl, H.T. Rêgo 32 (HVC).

\section{Prosthechea Knoules \& Westc.}

Chave para as espécies de Prosthechea do PNBN

1. Erva. 8,5-11 cm alt., pseudobulbo unifoliado 22.3. Prosthechea pygmaea

1. Erva $18-23 \mathrm{~cm}$ alt., pseudobulbo bifoliolado

2. Flores esverdeadas com máculas vinosas 22.2. Prosthechea pachysepala

2. Flores esbranquiçadas sem máculas vinosas 22.1. Prosthechea allemanoides

22.1. Prosthechea allemanoides (Hoehne) W.E.Higgins, Phytologia 82(5): 376. 1998. $\equiv$ Epidendrum allemanoides Hoehne, Bol. Agric. 34: 616. 1933.

Figura $4 \mathrm{c}$

Prosthechea allemanoides é uma planta epífita. Caracteriza-se por ter flores de coloração esbranquiçada com estrias vináceas no labelo, além de sépalas e pétalas lanceoladas. Foi coletada em flor no mês de março.

No Brasil até então só tinha sido encontrada na região Sudeste (ES, MG, RJ, SP) (Barros et al. 2016), sendo aqui citada pela primeira vez para o Nordeste do Brasil. Foi coletada em área de Mata Atlântica.

Material examinado: BRASIL. BAhIA: Boa Nova, Parque Nacional de Boa Nova, 23-III-2013, fl, C.O. Azevedo \& H.T. Rêgo 641 (HVC).

22.2. Prosthechea pachysepala (Klotzsch) Chiron \& V.P.Castro, Richardiana 3(4): 174. 2003. $\equiv$ Epidendrum pachysepalum Klotzsch, Allg. Gartenzeitung (Otto \& Dietrich) 23: 274. 1855. Figura $4 \mathrm{~d}$

Prosthechea pachysepala pertence a um complexo de espécies não muito bem definidas (Chiron \&
Castro-Neto 2003). É uma erva epífita, caracterizada principalmente pela coloração das sépalas e pétalas, que são amareladas com máculas vináceas e pelo labelo esbranquiçado com ápice róseo, além do formato do labelo que é trilobado. É similar à $P$. vespa, porém esta última ocorre em áreas de altitudes mais baixas (Chiron \& Castro-Neto 2003). Foi coletada em flor no mês de agosto.

No Brasil ocorre nas regiões Nordeste (BA) e Sudeste (MG, RJ, SP) (Barros et al. 2016). Na Bahia foi citada para a Serra das Lontras (Leitman et al. 2014). No PNBN foi coletada na área de Mata Atlântica.

Material examinado: BRASIL. BAHIA: Boa Nova, Parque Nacional de Boa Nova, 17-VIII-2013, fl, H.T. Rêgo 28 (HVC).

22.3. Prosthechea pygmaea (Hook.) W.E. Higgins, Phytologia 82(5): 380. 1998. E Epidendrum pygmaeum Hook., J. Bot. 1: 49. 1834.

Figura 4 e

Prosthechea pygmaea é uma espécie epífita e como o nome indica, é uma planta pequena, com cerca de 8,5 a $11 \mathrm{~cm}$ de altura. Possui pseudobulbo unifoliado e flores de coloração esbranquiçada, carnosas e labelo branco inteiro. Foi coletada em flor no mês de setembro.

Amplamente distribuída no Neotrópico, da Flórida ao Sul do Brasil (Pabst \& Dungs 1975). No Brasil ocorre nas regiões Norte (AM), Nordeste (BA, $\mathrm{PE})$ e em todos os Estados das regiões Sudeste e Sul (Barros et al. 2016). Na Bahia foi citada para a Serra das Lontras (Leitman et al. 2014), e no PNBN foi encontrada na área de Mata Atlântica.

Material examinado: BRASIL. BAHIA: Boa Nova, Parque Nacional de Boa Nova, 22-IX-2012, fl, C.O. Azevedo \& H.T. Rêgo 585 (HVC).

23. Rauhiella silvana Toscano, Lindleyana 8: 103. 1993.

Figura $4 \mathrm{f}$

Rauhiella silvana é uma espécie epífita com inflorescência pêndula, que possui flores assimétricas. Esta espécie se distingue das outras Rahuiella por apresentar labelo com várias papilas em forma de colar amarelo-alaranjado e coluna sigmoide. Foi coletada em flor no mês de novembro.

No Brasil ocorre nas regiões Nordeste (BA) e Sudeste (ES, RJ) (Barros et al. 2016). Na Bahia foi citada para o município de Itororó (Toscano de Brito 
1993), e durante o desenvolvimento deste trabalho foi encontrada na área de Mata de Cipó do PNBN.

Esta espécie foi avaliada quanto ao status de conservação pelo CNCFlora como em perigo (EN). O CNCFlora avaliou que existe risco de extinção pois a espécie apresenta um baixo número de registros de herbário. Além disso, as áreas de ocorrência da espécie são altamente ameaçadas, devido principalmente à expansão urbana desordenada, mineração e atividades agropecuárias. Segundo eles os municípios de Planalto (BA) e Linhares (ES), já perderam respectivamente $95 \%$ e $79 \%$ da sua cobertura florestal original. Encontrar a espécie dentro de um Parque Nacional é um dado importante para a sua conservação.

Material examinado: BRASIL. BAHIA: Boa Nova, Parque Nacional de Boa Nova, 25-XI-2012, fl, H.T. Rêgo 12 (HVC).

24. Rhetinantha notylioglossa (Rchb.f.) M.A. Blanco, Lankesteriana 7(3): 535. 2007. Maxillaria notylioglossa Rchb.f., Bonplandia 2: 16.1854. Figura $4 \mathrm{~g}$

Rhetinantha notylioglossa é uma erva epífita, suas flores são de cor creme-esverdeadas. Ela é caracterizada pelo formato do labelo, que possui lobo terminal triangular, com depósito de cera em forma de "V". Foi coletada em flor no mês de setembro.

Esta espécie tem distribuição ampla na América do Sul, ocorrendo da Venezuela até a Bolívia (Pabst \& Dungs 1977, Toscano de Brito \& Cribb 2005). No Brasil ocorre em Roraima, Pernambuco, Bahia e em todos os Estados das regiões Sudeste e Sul (Barros et al. 2016). Na Bahia foi encontrada nos municípios de Mucugê (Azevedo \& van den Berg 2007a), Lençóis (Toscano de Brito 1998) e na Serra das Lontras (Leitman et al. 2014). No PNBN foi coletada na área de Mata Atlântica.

Material examinado: BRASIL. BAHIA: Boa Nova, Parque Nacional de Boa Nova, 22-IX-2012, fl, C.O. Azevedo \& H.T. Rêgo 586 (HVC).

25. Sacoila lanceolata (Aubl.) Garay, Bot. Mus. Leafl. 28(4): 352. 1980. $\equiv$ Limodorum lanceolatum Aubl.,

Hist Pl. Guiane 2: 821. 1775.

Figura $4 \mathrm{~h}$

Sacoila lanceolata é uma espécie terrícola, com folhas basais em roseta. As flores são tubulares e pilosas, de coloração rosada e o labelo é inteiro. Foi coletada em flor no mês de outubro.
No Brasil ocorre nas regiões Norte (AC, AM, AP, PA, TO), Nordeste (AL, BA, CE, MA, PB, PE, PI, $\mathrm{SE}$ ), Centro-Oeste (DF, GO, MS, MT), Sudeste (ES, MG, RJ, SP) e Sul (PR, RS, SC) (Barros et al. 2016). Na Bahia já foi citada para a Chapada Diamantina nos municípios de Mucugê, Lençóis, Palmeiras, Piatã e Rio de Contas (Toscano de Brito 1998, Toscano de Brito \& Cribb 2005, van den Berg \& Azevedo 2005). Durante este projeto foi coletada na área de Mata de Cipó do PNBN.

Material examinado: BRASIL. BAHIA: Boa Nova, Parque Nacional de Boa Nova, 26-X-2013, fl, C.O. Azevedo \& H.T. Rêgo 667 (HVC).

26. Sarcoglottis ventricosa (Vell.) Hoehne, Arq. Bot. do Estado São Paulo n.s., form. maior 2: 146. 1952. $\equiv$ Serapias ventricosa Vell., Fl. Flumin. Icon. 9: t. 47. 1835.

Figura 5 a

Sarcoglottis ventricosa é uma espécie terrícola com folhas prostradas em forma de roseta. Possui inflorescência pilosa, portando entre 20 a 30 flores. As flores têm segmentos carnosos e pubescentes, de coloração marrom-esverdeada. Foi coletada em flor no mês de outubro.

No Brasil, até o momento, era conhecida apenas para as regiões Sudeste (MG, RJ, SP) e Sul (PR, RS) (Barros et al. 2016), sendo citada aqui pela primeira vez para o Nordeste, onde foi coletada em área de Mata de Cipó PNBN.

Material examinado: BRASIL. BAHIA: Boa Nova, Parque Nacional de Boa Nova, 26-X-2013, fl, C.O. Azevedo \& H.T. Rêgo 671 (HVC).

27. Scaphyglottis modesta Schltr., Repert. Spec. Nov. Regni Veg. 23: 46. 1926.

Figura $5 \mathrm{~b}$

Scaphyglottis modesta é uma espécie epífita, que forma touceiras ramificadas de ramicaules sobrepostos. Apresentam poucas flores, uma ou duas abertas por vez. As flores são carnosas, de coloração verde-amarelada com estrias vináceas, labelo amarelado e coluna com máculas vináceas. Foi coletada em flor no mês de março.

No Brasil ocorre nas regiões Norte (AM, PA, RO), Nordeste (AL, BA, CE, MA, PE), Centro-Oeste (MT), e em todos os Estados das regiões Sudeste e Sul (Barros et al. 2016). Na Bahia foi encontrada na Chapada Diamantina nos municípios de Lençóis, 
Mucugê e Palmeiras (Azevedo \& van den Berg 2007a, Toscano de Brito \& Cribb 2005), e no Sul do Estado, na Serra das Lontras (Leitman et al. 2014). No PNBN foi encontrada em área de Mata Atlântica.

Material examinado: BRASIL. BAHIA: Boa Nova, Parque Nacional de Boa Nova, 3-III-2014, fl, C.O. Azevedo \& H.T. Rêgo 676 (HVC).
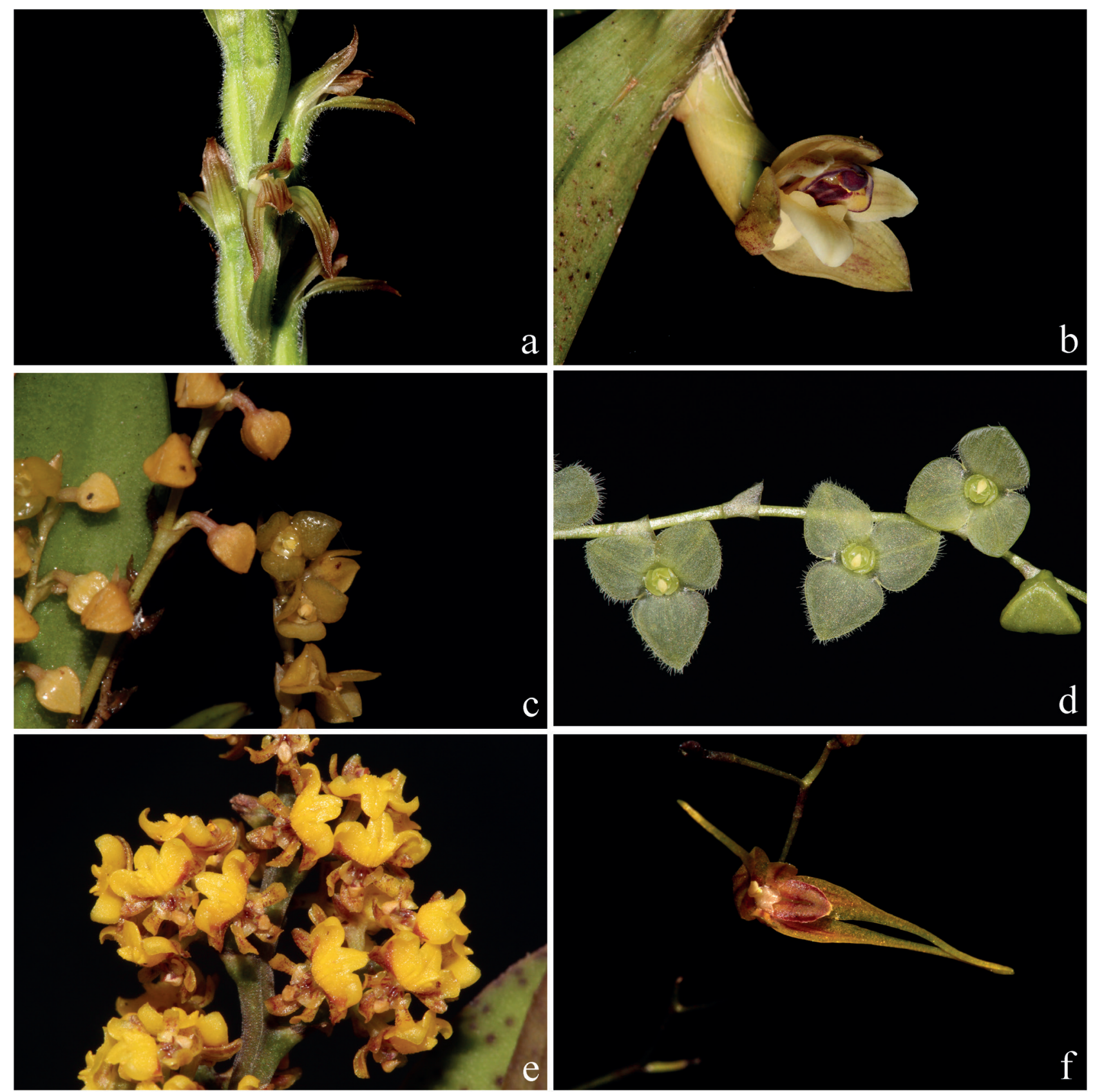

Figura 5. a. Sarcoglottis ventricosa. b. Scaphyglottis modesta. c. Stelis caespitosa. d. Stelis pauciflora. e. Trichocentrum pumilum. f. Trichosalpinx montana.

Figure 5. a. Sarcoglottis ventricosa. b. Scaphyglottis modesta. c. Stelis caespitosa. d. Stelis pauciflora. e. Trichocentrum pumilum. f. Trichosalpinx montana. 
28.1 Stelis caespitosa Lindl., Companion Bot. Mag. 2: 353.1837.

Figura $5 \mathrm{c}$

Espécie epífita, com inflorescência de 4 a $6 \mathrm{~cm}$ de comprimento, as flores são diminutas com sépalas de no máximo $3 \mathrm{~mm}$ de comprimento e apresentam coloração amarela. Foi coletada em flor no mês de setembro.

No Brasil até o momento só há registro para Minas Gerais, São Paulo e Bahia (Barros et al. 2016). Durante este estudo foi coletada no PNBN em área de Mata Atlântica.

Material examinado: BRASIL. BAHIA: Boa Nova, Parque Nacional de Boa Nova, 22-IX-2012, fl, C.O. Azevedo \& H.T. Rêgo 584 (HVC).

28.2. Stelis pauciflora Lindl., Ann. Mag. Nat. Hist. 12: 396. 1843.

Figura $5 \mathrm{~d}$

Stelis pauciflora é uma erva epifita. Possui flores esverdeadas, geralmente com tamanho e coloração das flores variável, contudo pode ser reconhecida pelo seu labelo com um múcron no ápice do bordo mediano e pelas sépalas semelhantes entre si e pilosas. Foi coletada em flor no mês de agosto.

No Brasil ocorre nas regiões Norte (AM), Nordeste (BA), Centro-Oeste (MS, MT), Sudeste (ES, MG, RJ, SP) e Sul (PR, SC) (Barros et al. 2016). No PNBN foi encontrada em área de Mata Atlântica.

Material examinado: BRASIL. BAHIA: Boa Nova, Parque Nacional de Boa Nova, 27-VIII-2013, fl, H.T. Rêgo 30 (HVC).

\section{Trichocentrum Poepp \& Endl.}

Chave taxonômica das espécies de Trichocentrum Poepp \& Endl. do PNBN

1. Folhas planas com máculas vermelhas, sépalas ca. $0,5 \mathrm{~cm}$ compr. ... 29.2. Trichocentrum pumilum

1. Folhas cilíndricas sem máculas, sépalas ca. $2,3 \mathrm{~cm}$ compr. ... 29.1. Trichocentrum caatingaense

29.1. Trichocentrum caatingaense (Cetzal, V.P. Castro \& Marçal) J.M.H.Shaw, Orchid Rev. Suppl., 122: 17. 2014. $\equiv$ Cohniella caatingaensis Cetzal, V.P.Castro \& Marçal, Syst. Bot. 37(1): 61. 2012.

Trichocentrum caatingaense foi descrita recentemente como parte de um complexo de espécies (Cetzal Ix et al. 2012), era conhecida anteriormente como Trichocentrum cebolleta (Jacq.) M.W. Chase \& N.H. Williams. É uma espécie epífita, que apresenta folhas cilíndricas e flores de coloração amarelada, caracterizada por apresentar o labelo pentalobado. Foi coletada em flor no mês de setembro.

Espécie endêmica do Brasil, conhecida para as regiões Norte (TO), Nordeste (BA, CE, MA, PB, PE, PI) e Sudeste (MG) (Cetzal Ix et al. 2012). Na Bahia foi citada para a Chapada Diamantina para os municípios de Morro do Chapéu (Bastos \& van den Berg 2012a), Palmeiras, Rio de Contas e Rio do Pires (Toscano de Brito \& Cribb 2005). Durante este estudo foi coletada em área de Caatinga no município de Boa Nova.

Material examinado: BRASIL. BAHIA: Boa Nova, Parque Nacional de Boa Nova, 20-IX-2013, fl, H.T. Rêgo 25 (HVC).

29.2. Trichocentrum pumilum (Lindl.) M.W. Chase \& N.H.Williams, Lindleyana 16(2): 137. 2001. $\equiv$ Oncidium pumilum Lindl., Bot. Reg. 11: t. 920. 1825.

Figura 5 e

Trichocentrum pumilum é uma espécie epífita, facilmente reconhecida por apresentar pseudobulbo inconspícuo, com apenas uma folha carnosa e de coloração verde com máculas marrons a avermelhadas. Suas flores são amarelas, com maculas castanhas, com cerca de 3 a 4 mm de diâmetro, além disso, seu labelo possui um calo central tetralobado. Foi coletada em flor no mês de abril.

No Brasil ocorre nas regiões Norte (PA), Nordeste (BA, SE), Centro-Oeste (DF, GO, MS, MT), Sudeste (ES, MG, RJ, SP) e Sul (PR, RS, SC) (Barros et al. 2016). Na Bahia já foi citada para Vitória da Conquista (Azevedo \& Marinho 2012) e no PNBN foi coletada na área de Mata de Cipó.

Material examinado: BRASIL. BAHIA: Boa Nova, Parque Nacional de Boa Nova, 10-IV-2013, fl, C.O. Azevedo \& H.T. Rêgo 658 (HVC).

30. Trichosalpinx montana (Barb.Rodr.) Luer., Phytologia 54(5): 396. 1983.

Figura $5 \mathrm{f}$

Trichosalpinx montana é uma espécie epífita. Apresenta flores de coloração amarelada com estrias vináceas. As pétalas são elípticas com margens irregulares e o labelo vináceo e trilobado. Foi coletada em flor no mês de setembro.

Endêmica do Brasil ocorre nas regiões Nordeste (PE), Sudeste (ES, MG, RJ, SP) e Sul (PR, SC) (Barros 
et al. 2016). Durante o desenvolvimento deste trabalho foi encontrada pela primeira vez para o Estado da Bahia, tendo sido coletada em área de Mata Atlântica no município de Boa Nova.

Material examinado: BRASIL. BAHIA: Boa Nova, Parque Nacional de Boa Nova, 22-IX-2012, fl, C.O. Azevedo \& H.T. Rêgo 581 (HVC).

31. Vanilla palmarum (Salzm. ex Lindl.) Lindl., Gen. Sp. Orchid. Pl. 436. 1840. EEpidendrum palmarum Salzm. ex Lindl., Gen. Sp. Orchid. Pl. 436. 1832.

Vanilla palmarum é uma espécie epífita, de hábito escandente. As flores são ressupinadas, de coloração amarela e labelo inteiro. Está sempre associada a palmeiras conhecidas popularmente com Licuri (Syagrus coronata). Foi coletada em flor nos meses de janeiro e fevereiro.

Citada para a Bolívia, Suriname e Brasil (Pabst \& Dungs 1975), onde ocorre nas regiões Norte (AC, AM, AP, PA, RR, TO), Nordeste (AL, BA, MA, PB, PE, PI, SE) e Centro-Oeste (GO, MS, MT) (Barros et al. 2016). Na Bahia já foi encontrada na Chapada Diamantina (Bastos \& van den Berg 2012a, van den Berg \& Azevedo 2005, Toscano de Brito \& Cribb 2005), e durante o desenvolvimento deste estudo foi coletada na área de Mata de Cipó e Caatinga do PNBN.

Material examinado: BRASIL. BAHIA: Boa Nova, Parque Nacional de Boa Nova, 24-II-2013, fl, fr, L.C. Marinho 393 (HVC); 11-I-2014, fl, H.T. Rêgo 33 (HVC).

\section{Agradecimentos}

Os autores agradecem a Josafá Sampaio e Josafá Filho pelo auxílio durante as coletas, ao ICMBio pela Licença (no. 34846-2) concedida, e à FAPESB pelo apoio financeiro (APP 0054/2011) e bolsa de Iniciação Científica concedida ao primeiro autor.

\section{Literatura citada}

Almeida, P.R.M., Góes-Neto, A. \& van den Berg, C. 2009. Variabilidade Genética em Populações de Encyclia dichroma (Lindl.) Schltr. e E. ghillanyi Pabst (Laeliinae, Orchidaceae). In: Anais do Congresso Brasileiro de Genética, São Paulo.

Amorim, A.M., Jardim, J.G., Goldenberg, R. 2014. Physeterostemon gomesii (Melastomataceae): the fourth species of this endemic genus in Bahia, Brazil. Phytotaxa 175: 45-50.
Azevedo, C.O. \& Marinho, L.C. 2012. Novos Registros de Orchidaceae para o Nordeste Brasileiro: Acianthera tricarinata e Cyclopogon variegatus. Sitientibus série Ciências Biológicas. 12: 1-11.

Azevedo, C.O. \& van den Berg, C. 2007. A Família Orchidaceae no Parque Municipal de Mucugê, Bahia, Brasil. Hoehnea 34: 1-47.

Barros, F., Vinhos, F., Rodrigues, V.T., Barberena, F.F.V.A., Fraga, C.N. \& Pessoa, E.M. 2016. Orchidaceae. Lista de Espécies da Flora do Brasil. Jardim Botânico do Rio de Janeiro. Disponível em http:// floradobrasil.jbrj.gov.br/jabot/floradobrasil/FB11833 (acesso em 23-V-2016).

Bastos, C.A. \& van den Berg, C. 2012a. A Família Orchidaceae no Município de Morro do Chapéu, Bahia, Brasil. Rodriguésia 63: 883-927.

Bastos, C.A. \& van den Berg, C. 2012b. Flora da Bahia: Catasetum (Orchidaceae). Sitientibus série Ciências Biológicas 12: 83-89.

Blanco, M.A. 2008. On Maxillaria Bomboizensis and Camaridium carinatum (Orchidaceae). Harvard Papers in Botany 13: 241-244.

Brasil. 2010. Decreto de 11 de junho de 2010. Disponível em http://www.icmbio.gov.br/portal/o-que fazemos/ visitacao/ucs abertas-a-visitacao/2587-parque-nacionalde-boa-nova.html (acesso em 4-II-2013).

Brasil. 2016. Relatório Parametrizado - Unidade de Conservação. Ministério do Meio Ambiente, Brasilia. Disponível em http://sistemas.mma.gov. $\mathrm{br} / \mathrm{cnuc} / \mathrm{index} \cdot \mathrm{ph} \mathrm{p}$ ?ido=relatorioparametrizado. exibeRelatorio\&relatorioPadrao $=$ true $\& i d U c=1908$ (10-X-2016).

Cetzal Ix, W.R.C., Fernández-Concha, G.C. \& Castro, V.P. 2012. Cohniella (Orchidaceae: Oncidiinae) South of the Amazon River. Systematic Botany 37: 58-77.

Chase, M.W., Cameron, K.M., Barret, R.L. \& Freudenstein, J.V. 2003. DNA Data and Orchidaceae Systematics: A New Phylogenetic Classification. In: K.W. Dixon, S.P. Kell, R.L. Barrett, \& F.J. Cribb. Orchid Conservation (eds.). Orchid Conservation. Natural History Publications, Kota Kinabalu, Sabah, Malaysia. pp. 69-89.

Chase, M.W., Cameron, K.M., Barrett, R.L. \& Freudenstein, J.V., Pridgeon, A.M., Salazar, G., Van den Berg, C. \& Schuiteman, A. 2015. An updated classification of Orchidaceae. Botanical Journal of the Linnean Society 177: 151-174.

Chiron, G.R. \& Castro-Neto, V.P. 2003. Révision der complexe Prosthechea vespa (Orchidaceae) pour le sud-est der Brésil. Richardiana 3: 163-180.

CNCFlora. 2016. Orchidaceae. In: Lista Vermelha da flora brasileira versão 2016. Centro Nacional de Conservação da Flora. Disponível em http://cncflora.jbrj.gov.br/ (acesso em IX-2016). 
Dressler, R.L. 1993. Phylogeny and Classification of the Orchid Family. Dioscorides Press, Portland.

Leitman, P., Amorin, A., Neto, L.M. \& Forzza, R.C. 2014. Epiphytic Angiosperms in a Mountain Forest in Southern Bahia, Brazil. Biota Neotropica 14: 1-12.

Luer, C.A. 1999. Icones Pleurothallidinarum XVIII. Systematics of Pleurothallis, subgen. Pleurothallis sect. Pleurothallis, subsect. Antenniferae, subsect. Longiracemosae, subsect. Macrophyllaeracemosae, subsect. Perplexae, subgen. Pseudostelis; subgen. Acuminatia. Addenda to Dracula, Lepanthes, Masdevallia and Pleurothallis. Miscellaneous new species of Dryadella, Lepanthes and Pleurothallis. Monographs in Systematic Botany, v. 76. Missouri Botanical Garden, Saint Louis.

Luer, C.A. \& Toscano de Brito, A.L.V. 2012. Miscellaneous New Species in the Pleurothallidinae (Orchidaceae) from Brazil. Harvard Papers in Botany 17: 307-315.

Mariano-Neto, E. 2005. As Florestas do Planalto de Conquista e Regiões Adjacentes. cap. 2. In: S. Campiolo. Biota das Florestas do Planalto de Conquista, Sudoeste da Bahia. Pro Bio Relatório Final. pp. 18-32.

Marinho, L.C. \& Azevedo, C.O. 2011. Acianthera saurocephala (Lodd.) Pridgeon \& M.W. Chase (Orchidaceae: Pleurothallidinae): Novo Registro para o Nordeste Brasileiro. Revista Brasileira de Biociências 9: 554-557.

Marinho, L.C. \& Azevedo, C.O. 2013. Orchidaceae na Reserva do Poço Escuro, Vitória da Conquista, Bahia, Brasil. Sitientibus série Ciências Biológicas 13: 1-14.

Morri, S.A., Silva, L.A., Lisboa, G. \& Coradin, L. 1989. Manual de Manejo do Herbário Fanerogâmico. 2 ed. CEPLAC, Ilhéus.

Novaes, A.B., Longuinhos, M.A.A., Rodrigues, J., Santos, I.F. 2007. Caracterização e Demanda Florestal da Região Sudoeste da Bahia. In: A.F. Santos, A.B. Novaes, I.F. Santos, M.A.A. Longuinhos (org.). Memórias do II Simpósio sobre Reflorestamento na Região Sudoeste da Bahia. Embrapa Florestas, Colombo. pp. 25-43.

Queiroz, L.P., Sena, T.S.N. \& Costa, M.J.S.L. 1996. Flora Vascular da Serra da Jibóia, Santa Terezinha - Bahia: O Campo Rupestre. Sitientibus série Ciências Biológicas 15: 27-40.

Pabst, G.F.J. \& Dungs, F. 1975. Orchidaceae Brasilienses. Kurt Schmersow, Hildesheim.
Pabst, G.F.J. \& Dungs, F. 1977. Orchidaceae Brasilienses. Kurt Schmersow, Hildesheim.

Pinheiro, F. 2005. Avaliação das relações intra e interespecíficas no complexo Epidendrum secundum e espécies afins (Orchidaceae) através de AFLP. Dissertação de Mestrado, Universidade de São Paulo.

Romanini, R.P. 2006. A família Orchidaceae no Parque Estatual da Ilha do Cardoso, Cananéia, SP. Dissertação de Mestrado, Instituto de Botânica da Secretaria do Meio Ambiente, São Paulo.

Sobral, M., Faria Jr., J.E.Q., Ibrahim, M.U., Lucas, E.J., Rigueira, D., Stadnik, A., Villaroel, D. 2015. Thirteen new Myrtaceae from Bahia, Brazil. Phytotaxa 224: 201-231.

Thiers, B. 2014. Index Herbariorum: a global directory of public herbaria and associated staff. New York Botanical Garden's Virtual Herbarium. Disponível em http:// sweetgum.nybg.org/ih/ (acesso em VI-2014).

Toscano de Brito, A.L.V. 1993. Rauhiella silvana - A New Species of the Subtribe Ornithocephalinae (Orchidaceae) From Bahia, Brazil. Lindleyana 8: 103-105.

Toscano de Brito, A.L.V. 1995. Orchidaceae. In: B.L. Stannard (ed.). Flora of the Pico das Almas: Chapada Diamantina, Bahia, Brazil. Kew: Royal Botanic Gardens. pp. 725-767.

Toscano de Brito, A.L.V. 1998. Orchidaceae. In: M.L.S. Guedes \& M.D. Orge (eds.). Checklist das Espécies Vasculares do Morro do Pai Inácio (Palmeiras) e Serra da Chapadinha (Lençóis), Chapada Diamantina, Bahia, Brasil. UFBA, Salvador, pp. 53-54.

Toscano de Brito, A.L.V. \& Cribb, P. 2005. Orquídeas da Chapada Diamantina. Nova Fronteira, São Paulo.

Toscano de Brito, A.L.V. \& Queiroz, L.P. 2003. Orchidaceae. In: D.C. Zappi, E. Lucas, B.L. Stannard, E.N. Lughadha, J.R. Pirani, L.P. Queiroz, S. Atkins, D.J.N. Hind, A.M. Giulietti, R.M. Harley \& A.M. Carvalho. Lista das plantas vasculares de Catolés, Chapada Diamantina, Bahia, Brasil. Boletim de Botânica, Departamento de Botânica, Instituto de Biociências, Universidade de São Paulo. 21: 396-397.

van den Berg, C. \& Azevedo, C. O. 2005. Orquídeas. In: F.A. Junca, L. Funch \& W. Rocha (eds.). Biodiversidade e Conservação da Chapada Diamantina. Ministério do Meio Ambiente, Brasília, pp.195-208. 